\title{
How Accurately Does Breeam Measure Sustainability?
}

\author{
Sarah Aspinall ${ }^{1}$, Begum Sertyesilisik ${ }^{2,3}$, Amr Sourani ${ }^{3}$, Ashley Tunstall ${ }^{4}$ \\ ${ }^{1}$ Interserve Construction Ltd, Wigan, UK \\ ${ }^{2}$ Istanbul Technical University, dept. of Architecture, Istanbul, Turkey \\ ${ }^{3}$ Liverpool John Moores University, School of Built Environment, Liverpool, UK \\ ${ }^{4}$ Bechtel Corporation, Prishtina Kosovo \\ Email: sarah.aspinall@interserve.com, b.sertyesilisik@ljmu.ac.uk, a.sourani@ljmu.ac.uk, \\ ajtunsta@bechtel.com, atunstall@bekmp.com
}

Received 2012

\begin{abstract}
The aim of this paper is to review the Building Research Establishment Environmental Assessment Method (BREEAM) in terms of how adequately it addresses sustainability. To achieve the aim, a literature review and semi-structured interviews with BREEAM assessors were conducted. Relevant literature has been reviewed to establish the meaning behind the concept of sustainability and to compare BREEAM with other environmental assessments in the built environment. An in-depth review of BREEAM and sustainability was then carried out through a series of semi structured interviews with seven experts in the field. It is concluded that BREEAM is an efficient tool in establishing the environmental performance of buildings through design and procurement. However it does not address the concept of sustainability in its entirety choosing to focus more on the environmental aspects. Some inconsistencies in its methods were also observed.
\end{abstract}

Keywords: BREEAM; CASBEE; Green Star; LEED; Sustainability

\section{Introduction}

Construction in the UK is a significant industry with productivity worth over $£ 100$ bn a year which accounts for $8 \%$ of GDP and provides employment for around 3 million workers [1]. The output of the construction industry has a major impact on ability to maintain a sustainable economy overall and has a major impact to on the environment [2]. [3] reported that construction business in the UK is responsible for nearly a third of all Industry-related pollution incidents, with construction and demolition waste alone representing $19 \%$ of total UK waste. Many buildings are environmentally inefficient and do not make best use of limited resources such as energy and water. The energy used in constructing, occupying and operating buildings represents approximately $50 \%$ of greenhouse gas emissions in the UK [3]. [4] described how carbon emissions have pushed global temperatures up by half a degree Celsius and if no action is taken then figures will only rise. As a result of the Stern Review [4], the Government introduced the Climate Change Bill with the aim of reducing $\mathrm{CO}_{2}$ emissions by $60 \%$ by 2050 . The UK is committed to achieving the vision of becoming a world leader in sustainable construction by reducing its carbon footprint and its consumption of natural resources, while creating a safer and stronger industry by training and retraining a skilled and committed workforce [2].

By 2016 the proportion of developed land in the UK is expected to rise from $10 \%$ to $12 \%$ which is higher than most other countries in the world. In this context sustainability of the built environment is critical to the nation and much can and should be done to encourage higher environmental standards [5]. It is due to this that building performance is now a major concern of professionals in the building industry and environmental building performance has emerged as one of the major issues in sustainable construction. The UK has set sustainability indicators that act as a guide to the direction of future Government policy. As a result a vast and expanding variety of tools and techniques to promote and appraise sustainable construction have emerged. The Building Research Establishment Environment Assessment Method (BREEAM) is one of the world's leading and most widely used environmental assessment method for buildings. BREEAM sets the standard for best practice in sustainable design and claims to have become the de facto measure used to describe a building's environmental performance. BREEAM is an ever evolving assessment tool that seeks to quantify sustainability in order to measure it, but how accurately does it truly measure sustainability? With the certification, advice and assessment fees alone costing a developer circa $£ 10,000$ (not including the cost of design elements), it is imperative that the method is investigated in order to justify such expense.

Little research has been carried out specifically on BREEAM and how proficient it is at addressing sustainability. The research presented in this paper analyses BREEAM and ascertains whether it is an accurate method of assessing building performance in terms of environmental impact and overall sustainability. The paper reviews the definitions of sustainability and other environmental performance assessment techniques and compares BREEAM against them. The paper then explores whether BREEAM successfully assesses and measures sustainability as defined.

\section{Sustainability and Environmental Assessment Methods Sustainability}

Within the construction industry terms such as sustainability, sustainable development and sustainable construction are used 
interchangeably. These terms focus on the ecological, social and economic issues of a building in the context of its community. Literature on sustainability bemoans the fact that the concept is broad and lacks a broad consensus; this is usually followed by the authors own preferred definitions, which in turn add to the lack on consensus [6]. The concept of sustainability has been used by the environmental movement since the 1970s. According to the Brundtland report, sustainable development is a development which meets "the needs of the present without compromising the ability of future generations to meet their own needs". The UN Division for Sustainable Development has adopted this definition. The Charted Institute of Building Services Engineers (CIBSE) [7] somewhat agrees with this definition however they also include terms such as "satisfy their basic needs" and "enjoy a better quality of life”.

According to [8], the term 'sustainability' originally belongs to ecology and it referred to the potential of an ecosystem to subsist over time. By adding the notion of development to the notion of sustainability, the focus of analysis shifts from that of ecology to that of society. The chief focus of sustainable development is on society, and it aims to include environmental considerations in the steering of societal change at the interface between the social, the economic, and the ecological aspects.

The UK Government's consultation paper Building a better quality of life emulates that of [8] on sustainable development. The UK Government states that sustainable development "is about ensuring a better quality of life for everyone, now and for generations to come”. It includes 4 main aims, namely [9]: social progress which recognises everyone's needs, effective protection of the environment, prudent use of natural resources, and maintenance of high and stable levels of economic growth and employment.

\section{Environmental Assessment Methods}

Environmental assessment methods seek to quantify sustainability by way of subjective scoring against a set of criteria. During the last decade, the building sector has witnessed the development of two types of environmental assessment tools, namely; the tools purely based on criteria scoring and the those tools based on life cycle assessment (LCA). The focus of this research is on building environmental assessments tools which are based on criteria scoring. The major principles of sustainable buildings are to reduce resource consumption, reuse resources, use recycled resources, protect nature, eliminate toxicity, apply life cycle costing, and focus on quality [10]. With these principles in mind, most green building criteria scoring systems deal with site selection, efficient use of energy and water resources during operation, indoor environmental quality, passive heating, cooling and ventilation, and the selection of environmentally preferable materials [11]. Various rating systems are available e.g. BREEAM and CASBEE (Comprehensive Assessment System for Building Environmental Efficiency). Some of these systems were created by modifying a single system, or integrating multiple systems [12]. Among the most established environmental assessment methods other than the UK's BREEAM are LEED, CASBEE and Green Star. LEED (the Leadership in Energy and Environmental Design) is a method that was developed in 1998 in the USA with a world wide application. CASBEE is a method that was developed in Japan in 2004 while Green Star is an Australian assessment method that was launched in 2003 [13]. The methods are briefly explained below.

BREEAM: The BRE (Building Environmental Efficiency) launched the first version of BREEAM in the UK in 1990; it has since then been launched internationally [14]. BREEAM identified that there is a large difference between the environmental impacts of a poorly performing building compared to what is achievable using current best practice. BREEAM aims at raising standards of the buildings [14]. Until the release of BREEAM, there had been little attempt, if any, to establish an objective and comprehensive means of simultaneously assessing a broad range of environmental considerations against explicitly declared criteria offering a summary of overall performance. The field of building environmental assessment has matured remarkably quickly since the introduction of BREEAM and the past 13 years have witnessed a rapid increase in the number of building environmental assessment methods in worldwide use [15]. BREEAM awards an environmental label after assessing buildings against a range of environmental issues covering impacts on the environment at global, local and indoor levels. For each category, there are a number of 'credits' available. Where buildings have attained or exceeded various benchmarks of performance, an appropriate number of credits are awarded. The relative importance of the credits awarded under each category is taken into account in the final score, which is interpreted in the form of an overall rating of pass, good, very good, excellent and outstanding (introduced in August 2008 revision). The scores are based on the following criteria [14]: Management, Health \& Wellbeing, Energy, Transport, Water, Materials, Waste, Land Use and Ecology, and Pollution. All BREEAM products are regularly updated to take advantage of new research and technology to reflect changing priorities in regulations and to ensure that BREEAM continues to represent current best practice. The popularity of BREEAM is increasing worldwide and is set to further increase in the UK as more and more funding bodies are making BREEAM certification a prerequisite. The key drivers for using BREEAM are to demonstrate the sustainability credentials to planning authorities, investors and customers, reduce energy and other running costs, improve staff productivity, make buildings more lettable and potentially realise higher rental incomes, make buildings more attractive to potential customers or tenants, preempt legislation, set targets for improvement and to improve the image and ethical investment policies. The time an assessment takes to complete varies according to the agreement between client and assessor, and the fee can vary between $£ 2,000$ and £10,000 (\$3971-\$19857). There is also a QA / certification fee which is paid through the assessor, to BRE. This fee varies, between $£ 740$ and $£ 1500$ ( $\$ 1469-\$ 2979$ ), according to the size of the building being assessed.

LEED:LEED is an environmental assessment method that has been developed by the United States Green Building Council (USGBC) in 1998 with the aim of developing high-performance, sustainable buildings and was largely inspired by and based upon the UK's leading model BREEAM. The USGBC is a non profit organisation committed to expanding sustainable building practices and its mission is to transform the way buildings and communities are designed, built and operated, enabling an environmentally and socially responsible, healthy \& prosperous environment that improves quality of life [16]. LEED contains the following major categories: sustainable sites; water efficiency; energy and atmosphere; materials and re- 
sources; indoor environmental quality; and innovation and design process. Since the initial launch LEED has been used to certify 1823 buildings in the US, under the 4 different ratings available - Certified (26-32 points), Silver (33-38 points), Gold (38-51 points) and Platinum (52-69 points). There are no weightings included in LEED, instead credits are worth one point and where there are multiple performance levels each level is worth one point. As there are no weightings the value of each issue is purely dependant on the number of points available. The lack of category weightings combined with the checklist approach that LEED uses to evaluate the impact of the materials mostly increases the weighting of the materials section in LEED compared to the other methods in this study. In LEED the section is worth nearly $1 / 5$ th of the final score whereas in both BREEAM and Green Star the materials section is worth just $1 / 10$ th of the final score which more closely reflects the relationship between the embodied and operational energy of a building. LEED is starting to appear as a method of choice within the UK construction industry. As global corporations compare assessment tools and look to qualify their worldwide building stock under one green rating, LEED is becoming more popular and favourable. Unlike BREEAM, which requires external assessment, LEED encourages consultants to have their staff trained as LEED-accredited professionals, who present a LEED-assessed design to be independently certified. This method has encouraged US firms to become more environmentally aware and influenced the speed of the green agenda by architects, engineers and other consultants. There are currently an estimated 25,000 accredited professionals in the US [17].

CASBEE: CASBEE is a relatively new system developed for the Japanese market. The family of assessment tools is based on the building's life cycle: pre-design, new construction, existing buildings, and renovation. CASBEE presents a new concept for assessment that distinguishes environmental load from quality of building performance. CASBEE results are presented as a measure of eco-efficiency or Building Environmental Efficiency (BEE). Results are plotted on a graph, with environmental load on one axis and quality on the other - the best buildings will fall in the section representing lowest environmental load and highest quality. Each criterion is scored from level 1 to level 5. The CASBEE technical manual [18] presents detailed definitions of each level for each criterion and includes reference material and calculation tools where needed. CASBEE major categories of criteria include: building environmental quality and performance; and building environmental loadings. In the manual, downloaded from the CASBEE website, there is little information on how the credits are actually assessed, other than the performance levels required.

Green Star: The Green Building Council Australia (GBCA) [19]'s objective is to promote sustainable development and the transition of the property industry by promoting green building programmes, technologies, design practices and operations. After an industry survey conducted by the GBCA, Green Star was developed to be a comprehensive, national, voluntary environmental rating scheme that evaluates the environmental design and achievements of buildings in order to: establish a common language; set a standard of measurement for green buildings; promote integrated, whole-building design; recognise environmental leadership; identify building life-cycle impacts; and raise awareness of green building benefits. Green Star has built on existing systems and tools from overseas mar- kets including the British BREEAM system and the North American LEED system. In addition, VicUrban, in its work with the Melbourne Docklands' ESD Guide, provided the intellectual property to assist in the development of a local system. Green Star has established individual environmental measurement criteria with particular relevance to the Australian marketplace and environmental context. Green Star covers a number of categories that assess the environmental impact that is a direct consequence of a projects site selection, design, construction and maintenance. The nine categories included within all Green Star rating tools are: management; indoor environment quality; energy; transport; water; materials; land use and ecology; emissions; and innovation. These categories are divided into credits, each of which addresses an initiative that improves or has the potential to improve environmental performance. Points are awarded in each credit for actions that demonstrate that the project has met the overall objectives of Green Star. Once all claimed credits in each category are assessed, a percentage score is calculated and Green Star environmental weighting factors are then applied. Green Star environmental weighting factors vary across states and territories to reflect diverse environmental concerns across Australia. The Green Star Certified Ratings available are: 4 Star Green Star Certified Rating (score 45-59) signifies 'Best Practice'; 5 Star Green Star Certified Rating (score 60-74) signifies 'Australian Excellence'; and 6 Star Green Star Certified Rating (score 75-100) signifies 'World Leadership'. Although Green Star certification requires a formal process, Green Star tools can be freely downloaded and used as guides to track and improve project environmental performance. As with LEED, 2 points are awarded where a member of the design team has received Green Star training and has achieved Accredited Professional status. Although an assessment can be carried out by any member of a project team, no score can be publicised unless the Green Star assessment is certified. In order to certify an assessment the GBCA commission a third party assessment panel to validate the self assessment rating and recommend, or oppose, a Green Star certified rating. Certification will only be awarded if a project achieves a score of at least 45 (Four Stars). The mechanisms used to calculate a whole building rating are identical to those employed by BREEAM in the UK.

\section{Research Methodology}

The aim of the research was to analyse BREEAM and ascertain whether it is an accurate method of assessing building performance in terms of environmental impact and overall sustainability. An extensive literature review has been conducted to ascertain the meaning of sustainability within the construction industry and to determine how sustainability can be measured. Furthermore, the most commonly used worldwide environmental assessment schemes were compared against the local UK benchmark BREEAM in order to ascertain where the BREEAM approach sits within the industry. In order to determine whether BREEAM successfully considers and measures sustainability as per the established definition, the primary data collection method used was in-depth, semi structured interviews. Questions were sent out to interviewees in advance. The questions were provisional and the overall aim of the interview was to gain as much knowledge from the expert as possible. Over 20 BREEAM assessors and industry professionals were contacted via email and telephone to take part in the research 
investigation. Only 7 of them agreed to be interviewed (Table 1). This amount was acceptable due to the fact that qualitative research stresses in-depth investigation where the emphasis is on quality rather than quantity, the objective was not to maximise numbers but to become "saturated" with information on the topic (Padgett, 1998). All 7 interviews were recorded using a Dictaphone and as a backup of this material notes were taken. The interviews were transcribed immediately to avoid the unnecessary loss of any data. The transcripts were then analysed based on an inductive approach geared to identifying patterns in the data by means of thematic codes. QSR NVivo was used to identify patterns and common themes in the interview data by assigning nodes to passages in order to interpret this in the form of meaningful findings. The identity of each interviewee was coded to allow individual identification and ease of presentation. The company names are not provided due to anonymity.

\section{Results and Discussions}

(Q1) (A), (B), (C), and (F) had the most experience in BREEAM all with 8-10 years experience. (D), (E), (F), and (G) the experience ranged from $1-4$ years.

(Qs 2\&3) (B) indicated that a small number attempt to achieve a BREEAM Excellent. All interviewees mentioned that the most popular rating aimed for is "very good" and that the rating which a developer sets out to achieve is usually achieved unless there are special circumstances. (A) emphasized that if a "very good" rating is set out to be achieved, then the companies tend to aim for a score between 70 and $74 \%$ as they don't want to invest any more money than what they have to. (G) stated that BREEAM is just seen as a means to an end in terms of achieving funding rather than developing sustainable buildings.

(Qs 4\&5) The results for questions 4\&5 varied considerably. (B) and (C) reported that in their experience the majority of projects were from private developers whereas (A), (D) and (G) have been more involved in State led projects (i.e. schools, hospitals and defence projects). (A), (E), and (F) identified that due to the current economic climate the amount of private developers has decreased in the past years.

Table 1.

Interviewees' characteristics.

\begin{tabular}{clc}
\hline $\begin{array}{c}\text { Identification } \\
\text { Prefix }\end{array}$ & \multicolumn{1}{c}{ Occupation } & $\begin{array}{c}\text { Experience in } \\
\text { assessing BREEAM }\end{array}$ \\
\hline (A) & $\begin{array}{l}\text { Energy and Sustainability Associate } \\
\text { Director }\end{array}$ & 9 years \\
(B) & Principal BREEAM Consultant & 10 years \\
(C) & MICE BREEAM \& Eco Homes & 8 years \\
(D) & Sustainability Manager \\
(E) & Principal Consultant & 1 year \\
(F) & Regional Design Manager & 3 years \\
(G) & Regional Site Manager \& & 8 years \\
\end{tabular}

(Q6) It was unanimous in the results that although some had used other environmental assessment methods from the UK such as NEAT (previous healthcare tool), none of them had used any other international tool. (A) and (D) were aware of LEED but had no working knowledge of the method. (D) commented that LEED is more accepted in international circles than BREEAM and that the BRE are working very hard to try and change that. (D) stated that BREEAM is prepared to be adopted for different circumstances whereas LEED is the same wherever you are in the world in terms of the weightings and categories.

(Q7) Sustainability was referred to as a meaningless "buzz word" and that "sustainable development" was the preferred, more relevant, term. It was found that all 7 responded in the same way, speaking about the combination of factors; environmental (G) and (F); social (A) and (D) and economic (A) and (D). (E) and (F) referred to how we should not compromise future generations. (C) stated that environmental issues are just a small percentage of what sustainability is all about. (B) believed that sustainability is making the best building you can, with the least impact on the environment within the financial budget.

(Q8) All of the interviewees believed BREEAM largely concentrated on just one aspect of sustainability which is the environmental impact of buildings. All interviewees believed that BREEAM did not pick up enough social and environmental aspects of sustainability. However it was important to note, as commented by (A), that BREEAM was initially produced to assess the environmental impact of buildings. However, (A) and (B) suggested that BREEAM needs to further develop to include more social and economic categories. (C) stated that practicably "they have got it just about right". However, (C) remarked that there are no monetary issues within BREEAM. (C) stated that: "For instance if you build something that is an excellent building but the cost of it is so high that you cannot let it or sell it then its unsustainable, that's the worst case of un-sustainability to build something that is not fit for use and if its too expensive for use then its not fit for use, this is something that BREEAM does not cover". (D) and (G) stated that in some cases BREEAM had become a box ticking exercise purely carried out to satisfy funding conditions. (A), (B), and $(G)$ claimed that it is difficult when using BREEAM to adopt site specific issues with the credits due to the inflexibility of the structure. $(\mathrm{G})$ also stated that when a credit requires the services of a specialist such as an ecologist or acoustician, there is sometimes conflict between the experts' opinion and what the BRE requires.

(Q9) Overall the opinion was that BREEAM is a tool that will develop over time. All interviewees believed that the correct step in that development was to bring in the post construction review and mandatory credits. The post construction assessment was seen as an insurance that developers and their contractors had carried out what they stated at the design stage of the project which is important when attempting to create more sustainable buildings. (A) and (B), two of the most experienced BREEAM assessors, thought that the Energy credit E1 which states to achieve a very good certification that a minimum of 6 credits needs to be achieved on that element is set very high. (A) commented that there are items in BRE which should have been mandatory to achieve certain levels. (A) questions whether the energy credit is set at the right level because the energy rating on a certificate varies depending on the building type. (A) stated that there is an argument that maybe 5 
credits should be mandatory for energy 1 .

(Q10) The data showed a mixture of responses to this question. It is clear that there is not one particular reason why BREEAM has been driven in a certain direction. (D) stated climate change and increased knowledge concerning climate change as one of the reasons why the August 2008 revision had become very much stricter on the Energy credits with the aim to reduce carbon emissions. It was felt by (A) and (D) that it was a natural progression for BREEAM as it seeks to deliver best practice; therefore BREEAM needs to adapt to stay ahead of the legislative minimum. (C) thought that the BRE needed to bring all their systems in line in a more standardised way and make them more robust. (C) in particular believes that a great deal of changes have been introduced due to assessor feedback. (C) argued that: "The BRE were having a lot of trouble controlling QA because every scheme is different. They have standardised the tool and the system. Credits change as industry changes because of changes in technology and in legislation. The reason that they brought the mandatory in was to bring it in line with the code (for sustainable homes).” The majority mentioned that they were looking for the mandatory post construction review. (E) commented that the build-up of significant criticisms of the scheme, (e.g. no requirement for $\mathrm{CO}_{2}$ improvement for 'Excellent') and the introduction of new issues (e.g. EPCs, Site Waste Management) were the key drivers to update the 2006 version of the method. (A) stated that the intention of BREEAM is that anything that is current standard practice or a legislative minimum standard would not score a credit under BREEAM. (D) believed the two major drivers were climate change agenda and making the system more robust.

(Q11) The interviewees spoke of the BREEAM in use and the post occupancy evaluation available from the BRE. All of the interviewees mentioned that BREEAM was designed to create sustainable buildings and is more concerned with the design and construction element. The Energy Performance Certification that was launched in August 2008 will go some way in measuring the energy efficiency of buildings against their potential however some of the industry experts feel that this step is too far ahead and is something that BREEAM was not meant to achieve. (D) commented that BRE so far do not monitor buildings. (D) thinks the next thing on the horizon from BRE will be the POE (the post occupancy evaluation) to have a robust system. $(\mathrm{C})$ remarked that they are struggling to actually implement BREEAM in use, and that there are very few buildings that have gone for an assessment under that heading. (C) further stated that the majority of companies which would consider that are very large companies with massive building stock.

(Q12) (C), (D), (E), and (G) are open to the fact that BREEAM certification can reduce the operational cost of a building however (A) and (B) believed that there is not enough evidence to support the concept. (F) claims that the BRE have promoted BREEAM as a cost neutral item and that industry reports and current experience do not come near to supporting this. (A) believed that it is very difficult to claim that BREEAM will reduce operational costs. (C) believed that there is signifycant evidence that sustainable buildings reduce the long term running costs. The interviewees suggested that instead of carrying out a full BREEAM, a non certified equivalent may be the most appropriate approach, e.g. carrying out sustainability brainstorming or using a sustainability checklist can give a developer $80 \%$ of the benefit by implementing the recommenddations without $20 \%$ of the cost.

(Q13) (B), (E), (F), and (G) were in the opinion that the BRE do not benchmark BREEAM against any other method. The BRE see themselves as the leading environmental assessment method in the UK. (A) stated that other environmental assessment methods benchmark themselves against BREEAM. (A) further stated that some international organisations in the UK prefer to use LEED; some might say that this is because LEED is a much more straightforward method than BREEAM and not as demanding. (D) commented that BRE see themselves as the ultimately benchmarkers. (C) believed that all the other options in the industry measuring sustainability are no where near as sophisticated as BREEAM. (C) stated that BREEAM is being rolled out internationally. (C) further stated that despite they used other tools, there is nothing that they have come across that is comparable to BREEAM.

(Q14) All of the interviewees mentioned that in addition to energy related concerns BREEAM also considers many other environmental concerns. (A) stated that unless there is a change in policy at a governmental level Part $\mathrm{L}$ can not be incorporated in BREEAM. (D) emphasized that building laws may be toughening up on carbon emissions and construction quality however BREEAM always maintains its status ahead of the building regulations as a standard of best practice. (D) further stated that if building regulations become tougher then so will BREEAM.

(Q15) The majority of interviewees [(A), (B), (D), (E), (F), and $(G)$ ] were of the opinion that the BRE do not do enough in terms of acquiring feedback etc. (E, G, A) thought that communication from the BRE is quite limited and impersonal. However, (C) has had a very different experience with the BRE, stating that the BRE are very good at listening and have introduced changes as a result of their feedback.

(Q16) The main changes to BREEAM desired were aimed towards the procedure of the assessment itself and not necessarily to do with the categories that BREEAM include (technical issues). All interviewees believed that the BRE had got the assessment about right in terms of the content but had a problem with the ambiguity of the manuals used for assessment. All interviewees were in the opinion that the manuals are not user friendly and fraught with differences in interpretation. (A) commented that the BREEAM manual is written in a much clearer fashion avoiding the need for interpretation. (A) further recommended that experienced assessor should be available in the BRE to provide interpretation on certain credits. (A) thinks that BRE do a good job with regard to the technical detail of the credits. (A) stated that there has been some confusion in some of the credits, especially when the credits refer to employing an expert. For example a point may be obtained under a BREEAM classification but an expert may have a different opinion to the BRE so who is right in that instance? Cost was also perceived as an issue. (C) stated that the people asking for the certifications are not following it through with acquiring certification. (C) commented that it would make the system better to be a lot cheap for developers and would encourage more developers to get on board with the scheme. (C) mentioned that the BRE is very "London Orientated" and all training/steer groups etc involves individuals travelling down to London for every occasion. (C) stated that this is frustrating to assessors and does not seem very much in line with that they are aiming to achieve "sustainability". (B) believes that as a scheme BREEAM is 
very good. However, (B) stated its shortcomings as follows: it can be generic on occasions and extremely frustrating; there is little inflexibility in their approach. (B) recommended that changes should be made on the ecology section as it is based purely on increasing the number of the types of plants focusing on the quantity of plants rather than quality. Accordingly, (D) stated that the manuals can sometimes create problems particularly around the ecology points because ecology is a notoriously complex area and it is difficult sometimes in the way BRE set things up and define things. (D) recommends that the BRE could do with a proper discussion/forum system for these items and that they need to embrace more modern technology and develop a BRE forum. (D) highlighted that the main factor that will improve sustainability is the Post Occupancy Evaluation which is a requirement to get a much more direct assessment of building sustainability. (E) desires a simpler target scheme using energy, water, ecology and culture and letting building regulations and planning cover the rest. (G) was not sure if the correct controls would be there if changes could be made to make the process cheaper and more attractive to implement.

The main difference between the assessment methods is the process of certification. BREEAM has trained assessors who review the evidence against the credit criteria and report it to the BRE, who validate the assessment and issue the certificate. While LEED does not require training, there is a credit available if an accredited professional. This is also the case in CASBEE. The role of the accredited professional is to help gather the evidence and advise the client. The evidence is then submitted to the USGBC which does the assessment and issues the certificate. Although LEED and Green Star have been heavily based on BREEAM, Green Star takes into account the diverse nature of its country of origin, Australia. The multiplicity in the UK is not as apparent as Australia but BREEAM does not take any location variances in account within its method. CASBEE has a very different approach altogether. Weightings are applied at the individual credit level. This addresses the problem that occurs when credits are deemed to be irrelevant to specific projects. More than half the credits in CASBEE do not have a BREEAM equivalent. It is therefore much more difficult to compare the rating bands of the two systems. Overall it is tougher to meet the highest rating in BREEAM than it is to meet the requirements of the alternative schemes when building in the UK. If a building is designed to meet the highest LEED or Green Star rating it is only likely to achieve a BREEAM rating of Very Good or Good which are the second and third highest ratings respectively. The two most popular schemes BREEAM and LEED share many common components. Both believe that early involvement of the assessor or accredited professional at the design stage is beneficial to the project and the final rating. Both schemes drive the market to improve building design. The judging criteria also keep pace with legislative developments and current best practice. There are differences in the way LEED calculates credits. The rating systems discussed all require varying levels of specialised sustainable design knowledge to be effectively used.

Data obtained through interviews revealed that most of the experts interviewed believe that BREEAM is a very good tool for assessing the environmental performance of buildings and that it is the only method that should be used in the UK specifically. Many of the interviewees alleged that the BRE does not tackle the whole of what sustainability is all about and that there is a distinct lack of economic and social aspects within the method that are significant in the overall concept of sustainability and sustainable development. There are some aspects of social wellbeing evident when evaluating indoor environment quality and items such as transport and cycle facilities, however it was recognised that there is no economic consideration at all. There is no category for a developer to consider whether a building is economically sustainable and if it is needed at all. It is consistently reported that there is not enough housing in the UK, however many city centre developments such as apartments and office spaces stay empty for months or even years. This is an element that is definitely missing from the current BREEAM. It needs to start considering if a building is really needed and if so is it fit for use. There is nothing more un-sustainable than to build something that is not fit for use or is too expensive to build, let or maintain.

Some of the interviewees stated that in some cases BREEAM had become a box ticking exercise purely carried out to satisfy funding conditions. The developer would then achieve the design and procurement certificate, issue this as evidence to the funding body, receive the funding and then never follow through with post construction certification. This is an error on the part of the funding bodies. The developer might not have carried out what was intended at the design stage and therefore the building may not be considered sustainable under full BREEAM certification.

Throughout the interviews, it was stated that the manuals used to assess BREEAM are too generic and inconsistent. Some claimed that it is difficult when using BREEAM to adopt site specific issues with the credits due to the inflexibility of the structure. It was also stated that when a credit requires the services of a specialist such as an ecologist or acoustician, there is sometimes conflict between the experts' opinion and what the BRE requires. As these inconsistencies cause frustration to the BREEAM advisor and the client, they should be addressed in any new revisions of BREEAM.

The findings revealed ambiguity in the BREEAM process as the majority of the assessment criteria are down to the interprettation of how a sentence or paragraph has been read by the individual. The experts recommended that the BREEAM manuals should be written in a much clearer fashion and that assessors should be available within the BRE with the ability to use their interpretation with regards to certain credits where the assessment criteria is open to subjectivity. It was also mentioned that the BRE are tackling this issue and in the 2008 revision sought to bring all the schemes in line in a standardised form. This sought to eliminate the subjectivity of BREEAM and variance across the BRE assessors. It had been suggested that the BRE were having difficulty controlling the Quality Assurance (QA) across a broad range of projects due to the uniqueness of projects. The BRE standardised the schemes and also brought in the innovation credits in order to provide some flexibility to the schemes.

The findings revealed that the BRE are not particularly interested in the environmental performance of buildings once they have received their post construction certificate. The cost of carrying out a BREEAM certificate can cost around $£ 10,000$ for certification, advice and assessment fees. The cost may not be as significant on a large project; however on much smaller schemes it may not be cost effective or appropriate to carry out a full certified BREEAM. It was suggested that instead of carrying out a full BREEAM, a non certified equivalent may be 
the most appropriate approach. This could enhance the sustainability performance of the project without incurring the BRE costs. More developers could consider this option when choosing how to introduce sustainability to their buildings.

\section{Conclusion}

Sustainable development (or sustainability) has been historically referred to as meeting the needs of the present without compromising the ability of future generations to meet their own needs. Therefore it is often associated with terms such as "maintaining" and "prolonging". The term is now not just seen to be about protecting the environment but is also concerned with protecting the economy and the society. This reveals the need to balance conservation of environmental resources with the issues of economic growth and social welfare.

Sustainability is a concept which is very difficult to quantify and measure. In recent times the sustainability agenda has become more important. The construction industry has come under pressure to become more sustainable and therefore environmental assessment methods have emerged in order to attempt to measure the sustainability of buildings. Buildings sustainability can be measured via criteria scoring, which is a subjective method that is open to skewed results. Environmental assessments have been developed in a world wide context and are being used by many industry and sustainability experts. The UK Government in particular has been using environmental assessment methods for over a decade and their popularity is only set to increase. Sustainability seeks to uphold our environment, economy and society. As particular focus has been on creating more sustainable building stock, environmental assessment tools have become the solution to measurement. However with a generic tool such as BREEAM it is difficult to adopt site specific issues with the credits due to the inflexibility of the framework. It is difficult for developers to stretch themselves in areas outside what is in the framework (the set criteria).

Three other environmental assessment methods from other countries were analysed and compared against the UK's prevailing method, BREEAM. The comparison showed that all methods were based on scoring certain criteria. The criteria set in each method were very similar, concentrating on the same categories. Other methods had been created based on BREEAM as this is the oldest established method in use. The UK Building Regulations are set much higher than other countries, therefore the interviewees revealed the tendency that a BREEAM certification was much more demanding and difficult to achieve than any of the other methods compared, thus generating a much more sustainable building stock.

The results revealed that BREEAM is perceived as a very useful tool when addressing the environmental performance of buildings; however it is perceived that it does not address the whole concept of sustainability and sustainable development. A chief focus of sustainable development is on society, as it aims to include environmental considerations in the steering of societal change at the interface between the social, the economic and the ecological aspects. BREEAM fails to include sufficient social and economic components to address the whole of concept of sustainability and sustainable development. Manuals were thought to be too subjective and ambiguous which has led to inconsistent judgments by the interviewed BRE assessors. There has been an attempt in the August 2008 to standardise the schemes under BREEAM and introduce some flexibility through client innovation. However, it was discovered that some BRE assessors do not have the experience to recognise true sustainable innovation and that the whole process has become too much of a box ticking exercise. BREEAM effectively assesses the issue of sustainability with regards to construction. It may not have been the intention for BREEAM to look at post occupancy in terms of environmental impact however the results of this research show that this may be something that should be made mandatory. In conclusion, BREEAM is a necessary tool in today's sustainability conscious society. There are some slight improvements identified that the field experts would like to see introduced, however it is felt that the BRE have got the method about right in terms of categories, weightings, credits and mandatory credits. It has already been stated that the method will continue to be revised and evolve with the aim of continuously improving and maintaining its lead on current legislation and offering best practice.

The current research has revealed certain issues that require attention in relation to environmental assessment methods in the built environment. Strategically there needs to be a focus aimed at promoting the use of not certified equivalent environmental assessment methods as a more sustainable approach to building assessment.

The UK Government should adopt a uniform approach and make the use of environmental assessments methods (either certified or non-certified) mandatory to all new construction projects and be included as part of building regulation compliance.

Developers should prove by certification or other means that sustainability and sustainable construction has been considered in the design and construction of all future building stock. This is imperative if the Climate Change Bill, with the aim of reducing $\mathrm{CO}_{2}$ emissions by $60 \%$ by 2050 , is to be realised.

The BRE should look into the content of the manuals and certification procedures of the method to eliminate inconsistencies in credits and address the quality control issues reported by the BREEAM and sustainability experts. There needs to be procedures in place to control the subjectivity of the method such as monitoring assessor qualification and training in order to reduce discrepancies between BRE assessors and advisers.

The sustainability of buildings should be addressed once they are occupied by either the building owner/occupier. More needs to be done to ensure that once constructed buildings are being operated in the most sustainable manner as much of the energy consumed by buildings are related to the occupation and operation stage.

The main limitation of the current study is that only seven interviewees participated in the research. For this reason, the findings can not be generalized. However, they provide useful insights and valuable perspectives. Further studies should be carried out to increase the efficiency of environmental assessment methods.

Appendix: Interview Questions

1 . How many years experience do you have in BREEAM assessing?

2. What have the results been for those projects?

3. What were the desired outcomes for the projects at design stage?

4. What proportion of the projects were state led and what were private led?

5. What sectors were the projects from - Health/Educa- 
tion/Commercial?

6. Have you used any other available systems to measure sustainable performance of buildings? Such as the GB Tool (Green Building Tool), LEED (Leadership in Energy and Environment Design) in the USA, CASBEE (Comprehensive Assessment System for Building Environmental Efficiency) in Japan, HQE (High Environmental Quality) in France and the most recently developed model VERDE method in Spain.

7. What does "sustainability in the construction industry" mean?

8. Do you feel the BREEAM sufficiently address the key issues of sustainability?

9. Do you agree with the revised August 2008 BREEAM weightings and new mandatory requirements?

10. What do you think were the key drivers to update the 2006 version of the method?

11. Once a building has been through the assessment process and been certified how does BRE monitor how sustainable the building is performing against its potential?

12. Do you think that some Employers believe that the upfront cost of BREEAM is offset by the assurance that operational costs will be reduced? Is it a fact that revenue costs cover the capital cost of the building?

13. Does BRE benchmark their assessment method against other methods in the industry?

14. Part L of the Building Regulations was revised in 2006 in order to improve energy efficiency by capping carbon emissions designed into the building and imposing minimum construction quality criteria. How does this regulation line up with BREEAM?

15. Do you get actively involved with focus groups etc to put forward your views for adapting and changing BREEAM? If not would you see this as a positive move?

16. Are there any changes to the method that you feel pernally would be beneficial and make the industry more sustainle?

\section{REFERENCES}

Vadera, S., Woolas, P., Flint, C., Pearson, I., Hodge, M., Jordan, W., Davies, M. (June 2008) Strategy for Sustainable Construction. Available: http://www.berr.gov.uk/files/file46535.pdf. Last accessed 20 December 2009.

HM Government (2008)

Environment Agency (2003). Position Statement: Sustainable Construction Environmentally Sustainable Buildings: Challenges and
Policies - a report by the OECD cited at: http://www.environment-agency.gov.uk/research/library/position/412 39.aspx [accessed 25/1/12]

Stern, N. (2006) The Economics of Change - The Stern Review. Cambridge: Cambridge University Press cited at: http://www.hm-treasury.gov.uk [accessed: 9/1/12]

Saunders, T. (2008). A Discussion Document Comparing International Environmental Assessment Methods for Buildings. BREEAM Publication.

Bell, S. and Morse, S. (2008) Sustainability Indicators. Measuring the immeasurable? Earthscan.

CIBSE (2007) Introduction to Sustainability. The Chartered Institution of Building Services Engineers London.

Reboratti, C.E. (1999) 'Territory, scale and sustainable development', in E. Becker and T. Jahn (eds) Sustainability and the Social Sciences: A Cross-disciplinary Approach to Integrating Environmental Considerations into Theoretical Reorientation, London: Zed Books.

Dickie, I. and Howard, N. (2000) Assessing environmental impacts of construction. Industry consensus, BREEAM and UK Ecopoints. Digest 446.

Kibert, C. (2007). Sustainable Construction. Hoboken, NJ: John Wiley \& Sons, Inc

Cole, R.J. (2000). "Building Environmental Assessment Methods: Assessing Construction Practices.” Construction Management and Economics, Vol. 18, pp 949-957.

Fowler, K.M., \& Rauch, E.M. (2006) Sustainable Building Rating Systems Summary, PNNL 15858. Pacific Northwest National Laboratory.

Sinou, M., and Kyvelou,S. (2006). Present and future of building performance assessment tools. Management and Environmental Quality: An International Journal, 17 (5), 570-586.

Building Research Establishment Environmental Assessment Method (2008). Cited at: http://www.BREEAM.org [accessed 30/1/12]

Cole, J R (2005) Building Environmental Assessment Methods: Redefining Intentions. Building Research and Information, 33 (5), September-October, pp. 455-467. Routledge, part of the Taylor \& Francis Group.

USGBC. (2007). LEED for Homes Program Pilot Rating System. Washington, DC:USGBC.

Building Services Journal (2008). Arup is taking the LEED, February 2008 cited at:

http://www.bsdlive.co.uk/story.asp?storycode=3104905 [accessed: 10/2/12]

Japan Sustainable Building Consortium (JSBC). (2006). Assessment Tool of CASBEE cited at: http://www.ibec.or.jp/CASBEE/english/method2E.htm [accessed 9/ 8/12]

Green Building Council Australia (GBCA). (2009) Green Star Rating Tools. Cited at:

http://www.gbca.org.au/green-star/rating-tools/green-star-rating-tools /953.htm [accessed 25/1/12] 